\title{
A função pedagógica do mito: reflexões sobre as personagens de Pandora e Eva
}

\section{The pedagogical function of the myth: reflections on the characters of Pandora and Eva}

\begin{abstract}
Eleno Marques de Araújo ${ }^{1 *}$, Samuele Pedro Gonzaga ${ }^{2}$, José Humberto Rodrigues dos Anjos ${ }^{1}$, Vania Maria de Oliveira Vieira ${ }^{3}$
\end{abstract}

\begin{abstract}
RESUMO
O objetivo deste ensaio é discutir a função pedagógica das narrativas míticas, a partir do paralelo entre os mitos de Pandora no mundo grego e a Queda ou Tentação de Eva no Paraíso. Buscou-se nas duas narrativas a evidência de linguagens que denotem sentimentos machistas de ambas as sociedades onde tiveram origens estes mitos. De per si, há uma semelhança entre as duas narrativas no que tange à contribuição da mulher para a desgraça do homem e do mundo que o cerca. A imagem feminina - representada por Pandora e Eva - aparece nos dois contextos como curiosa, frágil e facilmente enganada pela sedução do mal. Ressalta-se que um dos objetivos dos mitos é o caráter pedagógico, uma vez que eles sempre deixam algum tipo de ensinamento, o que também é evidenciado neste texto. Para além dessa questão buscou-se discutir a importância do mito em sala de aula, e de que maneira ele pode colaborar para a discussão de temas transversais, tais como o machismo, a depreciação da mulher em face ao homem, dentre outros. Trata-se de uma pesquisa bibliográfica que tem como base os pressupostos teóricos de Campbell (1990), Eliade (1989), Barthes (2015), Geraldi (2011), Silva (2017) entre outros.
\end{abstract}

Palavras-chave: Mito; Práticas Pedagógicas; Machismo.

\begin{abstract}
The aim of this essay is to discuss the pedagogical function of mythical narratives, based on the parallel between the myths of Pandora in the Greek world and the Fall or Temptation of Eve in Paradise. In both narratives, we searched for evidence of languages that denote sexist feelings of both societies where these myths originated. In itself, there is a similarity between the two narratives regarding the contribution of women to the misfortune of men and the world around them. The female image - represented by Pandora and Eva - appears in both contexts as curious, fragile and easily deceived by the seduction of evil. It is noteworthy that one of the goals of the myths is their pedagogical character, since they always leave some kind of teaching, which is also evidenced in this text. In addition to this issue, we sought to discuss the importance of the myth in the classroom, and how it can contribute to the discussion of cross-cutting themes, such as machismo, the depreciation of women in relation to men, among others. This is a bibliographical research based on the theoretical assumptions of Campbell (1990), Eliade (1989), Barthes (2015), Geraldi (2011), Silva (2017) among others.
\end{abstract}

Keywords: Myth; Pedagogical practices; Machismo.

\footnotetext{
${ }^{1}$ Centro Universitário de Mineiros - UNIFIMES - GO. *E-mail: profelenoaraujo@outlook.com

${ }^{2}$ Escola Municipal Lídia Queiroz Costa; Centro Mais Ensino - PE.

${ }^{3}$ Universidade de Uberaba - UNIUBE - MG.
} 


\section{INTRODUÇÃO}

O mundo apresenta-se como um problema a ser decifrado aos olhos dos humanos que desde a antiguidade buscam desvelar os segredos que cercam tais mistérios. Em tempos mais remotos em que o conhecimento das pessoas não ultrapassava os limites do cotidiano, os fenômenos eram explicados de forma simples, pois os acontecimentos eram próximos da vida diária que o povo levava. No entanto, as forças da natureza rompiam com essa harmonia trazendo o mistério de situações desconhecidas, tais como: os trovões, as pestes e a própria chuva. Para Matallo Junior (2003, p. 30):

É objetivo do mito, assim como da ciência, explicar o mundo, fazer seus fenômenos inteligíveis. Como a ciência, seu propósito é suprir o homem com os meios de influenciar o universo, de permitir sua apreensão material e espiritual. Dado um universo cheio de incertezas e mistérios, os mitos intervêm para introduzir um elemento humano.

Tomando como assertiva a definição de Matallo Junior (2003), haja vista que o mito deseja explicar a realidade, torná-la compreensível e educar a partir dela, facilitando assim a vida em um mundo misterioso e por vezes sombrio e assustador, podemos depreender a ideia do mito como uma função pedagógica, ou seja, capaz de promover uma reflexão e um aprendizado.

As narrativas míticas estão inseridas em um locus de criação, uma vez que elas existem para responder a existência de algum ente surgido no mundo por meio das cosmogonias, ou teogonias. No contexto grego o poeta rapsodo era o responsável por trazer a público tais narrativas educando, sobretudo as crianças, a conhecer como foram criadas pelos deuses. De certa forma é possível inferir ainda, que foi a incapacidade científica de explicar os fenômenos, que deu força aos mitos. Dessa forma, ao não encontrar explicação para determinadas situações, os homens fabulavam e atribuíam uma versão fantasiosa para explicar a realidade.

As crianças têm uma inquietação natural para conhecer. Fazem perguntas sobre todas e quaisquer coisas, sobre as que já conhecem, ou as que são desconhecidas. Formulam perguntas fáceis, e por vezes, difíceis. Se as respostas são alcançadas, elas se 
satisfazem e dão por encerrada a questão, nesse caso, passam a dominar a explicação, o misterioso e desconhecido, que doravante será visto como familiar e não mais assustador.

Entretanto, com a mitologia, há que se advertir, não acontece exatamente assim, porque o poeta rapsodo não podia ser questionado. Sua explicação era sempre verdadeira porque de alguma forma ele participava do mundo das divindades que the tornavam conhecidas as "histórias" in illo tempore. ${ }^{3}$ Neste interim, suas narrativas eram sempre autênticas e inquestionáveis. As contradições, a fabulação, e a ingenuidade dentre outras características presentes nas histórias, eram dispensadas.

$\mathrm{Na}$ atualidade não é possível simplesmente julgar como irrelevante as narrativas míticas, uma vez que, em seu tempo elas respondiam as necessidades de conhecer e davam conta de amenizar o espanto do humano em meio a situações que pareciam caóticas. Portanto, ter o mito como ponto de partida para outras reflexões é muito importante, pois a linguagem metafórica com que ele se reveste, bem como sua capacidade de encanto tem um sentido pedagogizante.

Esse artigo é dividido em três sessões. Na primeira dialogamos sobre o contexto criacionista, analisando as figuras de Eva e Pandora e os desdobramentos possíveis para compreendê-las. Na segunda, abordamos o mito a partir de um viés pedagógico, discutindo sua capacidade criadora e reflexiva. Por sim, na última sessão, elaboramos algumas considerações sobre o tema.

\section{Pandora, Eva e os ecos do contexto criacionista}

Ao escrever sobre os mitos, símbolos e arquétipos presentes nos contos de fadas, Nelly Novaes Coelho (2003, p. 86) afirma que "o pensamento mítico nasceu como uma das primeiras manifestações do que seria mais tarde o pensamento religioso, isso é, a consciência do homem em face de um Princípio Superior Absoluto que o explica e o

\footnotetext{
${ }^{3}$ Mircea Eliade afirma em sua obra $O$ Sagrado e o Profano que esta referência indica um tempo imemorável quando os deuses criaram as realidades existentes.
} 
justifica". Portanto, temos o conhecimento mítico, resguardadas as suas devidas proporções culturais, muito próximo ao conhecimento religioso.

Sendo assim, conscientes de que os mitos são cercados de uma situação criadora, pois a narrativa traz em seu bojo respostas para indagações fundadoras - Como? Quando? e Por que? - chegamos nas narrativas de Eva e Pandora, que se destacam em um contexto bem maior que o de suas próprias existências.

Ambas as narrativas encerram um momento de criação geral do mundo ou do kósmos. Zeus ao decidir criar Pandora, uma vez que não havia ainda mulher na terra, remete a história para um momento onde tudo ainda estava sendo criado. No entanto, ele não a cria como um gesto mágico onipotente, mas, conta com os dotes e habilidades de outros deuses que corroboram na criação da primeira mulher, dando à Pandora determinadas dádivas:

Todos os Deuses, sob as ordens de Zeus, concorrem ao nascimento de Pandora, a primeira mulher: Eu presentearei os homens, diz Zeus com um mal e todos, no fundo do coração, desejarão cercar de amor sua própria infelicidade... Ele diz e cai na gargalhada, o pai dos deuses e dos homens... ordena ao ilustre Hefestos que, sem demora, umedeça com água um pouco de terra e aí coloque a voz e a força de um ser humano e que forme, à imagem das deusas imortais, um belo corpo amável de virgem; Atenas lhe ensinará seus trabalhos, o ofício que tece mil cores, Afrodite de ouro sobre sua fronte espalhará a graça, o desejo doloroso, as preocupações que despedaçam os membros, enquanto que um espírito imprudente e um coração artificioso serão, por ordem de Zeus, colocados nela por Hermes, o Mensageiro, matador de Argo. Ele fala e todos obedecem ao senhor Zeus, filho de Cronos. E, em seu seio, o Mensageiro, matador de Argo, cria mentiras, palavras enganadoras, coração manhoso, assim como o quer Zeus, com pesados ribombos. Depois, arauto dos deuses, ele põe nela a palavra e a essa mulher ele dá o nome de Pandora porque são todos os habitantes do Olimpo que, com esse presente, fazem da desgraça um presente para os homens. (CHEVALIER, p. 485. Grifos originais).

A matéria prima da qual Hefestos usou para moldar o corpo de Pandora foi a argila. Com um pouco de água ele umedeceu uma porção de terra e com este material criou a primeira mulher. Depois, as divindades foram agregando, cada uma, algo de especial. Entretanto, há de observar que o propósito da criação daquele ser, carregava o pretexto da punição dos homens que já povoavam a terra.

A criação de Eva, por Yhwh, em Gênesis, está inserida em outro contexto cultural, daí decorrem diferenças basilares em relação à narrativa grega de Pandora. A primeira 
questão é ressaltar que temos dois relatos da criação de Eva, sendo um em Gênesis, capítulo 1, versículos de 26 a 31, e outro no mesmo livro capítulo 2, versículos de 4 a 24 .

Na primeira narrativa, a criação surge no desfecho dos seis dias da criação, sendo homem e mulher criados de uma só vez: "Deus criou o ser humano à sua imagem, à imagem de Deus o criou. Homem e mulher ele os criou". Diferente da primeira narrativa, na segunda, Deus cria o homem, Adão, e somente depois em função de sua solidão é que cria a mulher, para ser sua companheira.

Na criação de Eva: Yhwh é o único Demiurgo, artífice que primeiro molda o varão do pó da terra, da argila, igual que Pandora na mitologia grega. Mas neste segundo relato, a matéria prima de Eva, é a carne, ou o osso de Adão. Depois de Adão haver nomeado todos os entes criados por Deus e não ter encontrado na obra criada alguém que lhe fosse semelhante, o Criador fez o homem dormir e retirou dele, uma parte, com a qual faz a mulher. Quando, porém, acordou do sono profundo recebeu como presente sua companheira e exclamou: "esta sim é osso de meus ossos e carne de minha carne e a chamou Eva".

Em ambas as narrativas a Mulher é produto do "Masculino". Zeus por seu capricho quis punir o homem por sua desobediência em usar o fogo, que era de domínio exclusivo dos deuses. Para isso usou do artifício do fogo da paixão, criando a mulher para atrair e seduzir o masculino. $\mathrm{O}$ feminino arrastaria o coração do homem por um desejo eterno. E com isso o poderoso Zeus sentir-se-ia vingado do humano. Consequentemente, Pandora representa a origem dos males da humanidade:

eles vêm através da mulher, segundo esse mito, e esta foi modelada sob a ordem de Zeus como um castigo pela desobediência de Prometeu, que tinha roubado o fogo do céu para dar aos homens. Segundo a lenda de Pandora, o homem recebeu os benefícios do fogo, contra a vontade dos deuses, e os malefícios da mulher, contra a sua vontade. A mulher é o preço do fogo. Não há lugar para se reter mais que os símbolos incluídos na lenda: ela mostra a ambivalência do fogo, que deu à humanidade um imenso poder, mas que pode voltar-se para desgraça bem como para sua felicidade, dependendo de o desejo dos homens ser bom ou perverso. E é frequentemente a mulher que desvia o fogo no sentido da desgraça. O fogo simboliza também o amor, que todo ser humano deseja, mesmo que sofra em função dele. O homem, que arrebatou o fogo dos deuses, suportará a queimadura pelo fogo do seu desejo. Pandora Simboliza o fogo dos desejos que causam a desgraça dos homens. (CHEVALIER; GHEERBRANT, 2009. p. 680-681). 
Yhwh ao perceber a solidão do primeiro homem decidiu criar a primeira mulher: Eva. A finalidade dessa criação é distinta da de Pandora. Na Mitologia grega, era a punição do homem, aqui na narrativa judaica o objetivo era fazer para o homem uma companheira, que pusesse fim à sua solidão. No entanto, não foi esse o desfeche da narrativa, pois igual a Pandora, Eva possibilitou a entrada do mal no mundo. Desse modo, os males e o pecado, são frutos da desobediência dessas duas primeiras mulheres.

O princípio da proibição fica caracterizado nas duas narrativas, pela ação do feminino em contraposição a uma ordem masculina. Pandora ao ser enviada a Epimeteu, recebe uma caixa com orientações de que na mesma haviam coisas maravilhosas. Porém, há a normativa de que ela nunca poderia abri-la. Desse modo a narrativa é articulada de maneira que Pandora ao mesmo tempo que proibida é incentivada a descobrir o que de tão maravilhoso estaria guardado na caixa. Sua curiosidade, algo próprio do humano que sempre quer conhecer e desvelar o mistério, ficou profundamente desejosa a abrir a caixa. A proibição não faz sentido diante do desejo e da curiosidade.

Desejar o bom, o maravilhoso, é sempre agradável, e isso torna Pandora uma mulher corajosa, fato que a faz abrir a caixa. Essas características também estão presentes nos olhos de Eva, força motriz para que ela também descumpra uma regra posta.

No segundo relato judaico da criação do mundo, não houve a proibição para Eva, mas sim para Adão, antes do nascimento de Eva. Seria papel do homem zelar pela mulher? Teria Adão que conversar, ensinar a Eva tudo o que ele viveu e recebeu de Yhwh, dizer a ela que nunca poderia comer do fruto da árvore que estava no centro do jardim? Se Adão cumpriu, ou não essa função, a descrição da criação não conta estes detalhes.

Na primeira narrativa, em que homem e mulher foram criados conjuntamente, ambos foram instruídos a não comerem os frutos da árvore do conhecimento do bem e do mal. Entretanto, a queda, isto é, o pecado acontece depois da inserção do segundo texto que narra a criação. Dicotomicamente, existem dois relatos da criação e um só da desobediência e pecado.

Ao descrever a situação de pecado, que representa o mal no mundo, o texto que trata de sua origem responsabiliza a mulher pela entrada do mal na vida do ser humano. Em primeiro lugar Yhwh chama a atenção do homem indagando-o: "que fizestes? Por acaso comeu do fruto proibido?”. A resposta dada ao Criador está carregada de uma 
linguagem que retira do homem sua liberdade de ação, culpabilizando Eva: "A mulher que Tu me destes me fez comer".

Na resposta dada a Yhawh o masculino isenta-se de toda a culpa repassando para Eva a responsabilidade. Se o macho em sociedades patriarcais é o guardião da fêmea, então Adão não zelou por sua responsabilidade, deixando Eva livre para fazer o que julgasse conveniente. Entretanto, o que é perceptível é o oposto. Todas as pessoas são dotadas da capacidade de discernimento e da liberdade de ação. Adão necessariamente não comeu o fruto porque Eva o deu, mas o comeu porque foi livre para comê-lo. Porém, a condição machista da sociedade patriarcal em que o texto foi composto, quer isentar do homem esta responsabilidade e atribui à mulher o papel de sedutora.

O contexto da criação também está implícito no mito de Pandora, porém em uma situação inversa a de Eva. O objetivo da criação de Pandora foi a punição do homem. Zeus quis castigar o ser humano por havê-lo desobedecido usando o fogo. A primeira mulher foi, já de início, objeto de castigo, ou seja, de mal para o homem. Foi Zeus quem a idealizou com esta finalidade. Seu destino, ou missão era o de desgraçar a vida de Epimeteu.

Uma das características da mitologia grega é a recompensa, ou a punição que os deuses fazem aos que os obedecem ou, desobedecem. Como na narrativa da criação judaica havia a proibição de não comer do fruto proibido, no mito de Pandora também o humano não podia usar o fogo.

Na narrativa judaica há um diálogo entre o Criador e a criatura e o castigo só lhe é imputado com a assumência da falta, isto é, da desobediência. Em Pandora a decisão de Zeus é tomada sem a premissa da escuta, sendo a primeira mulher predestinada a trazer em sua caixa tudo o que não prestava. A que ressaltar que ela recebeu a orientação ou uma nova proibição de não abrir a caixa. Mas também a que lembrar que Pandora foi, por Zeus, dotada de curiosidade, este 'dote' especial provocou nela o desejo de conhecer ou saber sobre o conteúdo que havia na caixa. Também Eva comeu o fruto no desejo de conhecer. A proibição afirma que ao comer morreria, e na intervenção da serpente, fica evidente a questão do conhecimento. "Se comerdes seres como deuses, e não morrereis". Ela comeu para conhecer, saber discernir. 
Quando Pandora abriu a caixa e liberou o conteúdo que lá existia, também ela pode conhecer e discernir. Porém, como a todos os seres humanos o primeiro discernimento é o de que não devia ter feito, bate o arrependimento. Com Eva não foi diferente. Se em Pandora entram as desgraças no mundo: as pestes, as guerras, a inveja, a fome e tantos outros males. Na narrativa de Eva entra o castigo do trabalho, a dor do parto, a submissão ao masculino etc.

A escusa no relato de Eva é algo muito interessante que merece ser destacado. Esta questão não está presente no mito de Pandora, até porque sua finalidade era de ser um instrumento de castigo para Epimeteu, que representa o ser humano na narrativa.

Eva comeu o fruto e o deu a Adão para que comece também. É de ressaltar que no discurso aparece a figura sedutora da serpente, que por sua vez também é um animal do gênero feminino: "a serpente". No diálogo entre elas aparece na primeira pergunta uma dúvida por parte da serpente, mas que é extremante provocadora: "É verdade que Deus disse: 'Não comais de nenhuma das árvores do jardim?” (Gn 3, 2). A pergunta já leva a evidência da resposta. Pois é uma pergunta retórica. Se o ser humano não comesse das frutas ele deveria alimentar-se de que? Seria o humano um carnívoro por excelência?

Para responder as questões a cima recorreremos ao texto do final do primeiro relato da criação em Gn 1, 29 "Deus disse: 'Eis que vos dou, sobre toda a terra, todas as plantas que dão semente e todas as árvores que produzem seu fruto com suas semente, para vos servirem de alimento"”. Não aparece neste primeiro relato a proibição excetuando a árvore do centro do jardim de Édem. A serpente, ao interrogar Eva pergunta por todas as frutas, ou seja, por todas as plantas. No texto de Gn 1, 29 o humano deveria ser vegetariano, uma vez que não tem animais como alimento. O versículo seguinte a este Gn 1, 30 não refere mais ao humano, mas sim aos animais.

A Serpente ao perguntar a Eva se estava proibida por Deus de comer de todas as frutas, porque já sabia que os humanos comiam das frutas, porém queria desmistificar a proibição do fruto central, que talvez observando, não tivesse visto Eva ou Adão apanhar dos frutos da árvore do centro do Jardim.

Enfim, fundamentando nosso pensamento na afirmação de Marconi e Lakatos (2005), que todas as sociedades em diferentes épocas de sua história mudaram sua forma e concepção de governo ora sendo matriarcal e por vezes na grande maioria patriarcal. 
Hoje de forma quase generalizada vivemos em um contexto patriarcal de forte cunho machista. Muito tem sido feito na tentativa de dar a mulher uma igualdade de direito, lugar de igualdade nos espaços e debates onde se constroem as leis e delineiam os princípios constituintes da educação nas diferentes nações, aqui e ali pelo mundo afora.

Ao revezar a concepção de governo muda também a cosmovisão, as relações na sociedade tendem a ser definidas por uma estrutura lógica da forma do gênero que exerce o governo. Isso fica mais evidente com os sistemas patriarcais que se desdobram em estilos linguísticos machistas.

Observa-se, entretanto, que a humanidade tem uma dívida com a Mulher, uma vez que a relegou à situação inferior e diminuída em relação ao Homem. Afirmamos que é a humanidade porque fruto de uma educação machista milenar, muitas mulheres inculcaram e aceitam resignadas a condição inferior imputada pelo homem. Neste sentido, o gênero humano precisará de uma longa caminhada para que o dano causado à Mulher seja superado.

Ao destacar esses enfoques acerca do mito com múltiplas interpretações e historicidades com perspectivas teológico-filosófico, no campo da educação não se torna diferente em termos de busca pela verdade das coisas. As verdades filosóficas e teológicas permitem ao homem racional adentrar ao conhecimento por meio das indagações e busca pela verdade. Com o surgimento da filosofia, os gregos buscam a verdade das coisas e tem como finalidade descobrir a existência de todas as coisas, sobretudo, dar uma explicação ao início do Kosmos. Até então, as respostas obtidas pelos gregos, eram através das manifestações dos deuses, a teogonia.

Para todo efeito, o mito tem a função de uma narrativa com a finalidade de expor um conteúdo histórico, partindo de princípios existenciais e cosmológicos. Enfim, a linguagem com cunho filosófico-teológico, existem elementos pedagógicos que são essenciais para o aprendizagem daqueles que buscam de certa maneira um conhecimento específico, ou seja, no campo da educação a criança-aluno aprende a partir de situações de verdades mitológicas. 


\section{O MITO COMO UMA PRÁTICA PEDAGÓGICA}

Para usarmos os estudos dos mitos em sala de aula teremos que reorganizar os posicionamentos estruturais dos currículos. Pois, são meios estruturantes que servem de alicerces para o exercício da profissão de professor com os alunos nas tarefas pedagógicas diários nas atividades educacionais. Para tanto, são necessárias mudanças na elaboração dos conteúdos, na formação do professor e didática entre outras mudanças, que pertencem ao bloco curricular das IES e escolas.

Precisamos pensar para além de um 'currículo facilitador ou norteador' que vigora na maioria das universidades e escolas de nosso país. Mas, também usado por educadores(as), o que compromete os resultados da aprendizagem dos educandos, sobretudo, quando o quesito abordado for a relação com o outro, visto como diferente de si mesmo. Aqui estão as imbricações conhecidas como diversidade, pluralismo e/ou multiplicidade cultural.

Apoiando-se no campo da didática como se ela fosse um mero instrumento de trabalho, fragmentam os conteúdos tornando as aulas entediantes e trocas de assuntos, pertencem ao grupo de pensamento hegemônico e ditador que imperam na educação moderna formando futuros educandos em meros técnicos entre outros termos que desqualificam e exercem a educação como uma prática universalista. Neste texto queremos demonstrar que os mitos têm um caráter pedagógico, daí que as práticas educacionais tendo como pano de fundo o mito corroborando como conteúdo que poderá ser utilizado| em sala de aula.

Nessa perspectiva, apresentaremos as obras de Freire (1992) Spivak (2010), Candau (2013) Nogueira (2012) e Walsh (2007), uma vez que são propostas formadoras e dão contribuição aos profissionais de educação que estarão em contato direto com o corpo discente como também, as práticas em sala de aula mediando ações educacionais que o estudo com o mito necessitará. Haja vista, os autores a cada momento constroemdescontroem-reconstroem seus projetos científicos repletos de novas teorias. Interpretam resultados positivamente e, com isto nos ensinam a fazer com que a educação no Brasil seja cada vez mais interessante e de qualidade, sendo referência no mundo. Desta forma, 
retroalimentam os resultados necessários afirmando que a temática educacional é inesgotável e inteligível.

Ressalta-se o discurso pesquisado nesta abordagem que descortina o 'mito' abrindo o seu vasto campo de leitura. Negando sua participação como um monólogo a ser servido, como se existisse apenas um desfecho. Consideramos desde já, as multiplicidades interculturais do mundo, já que entendemos, que somos na heterogeneidade, negando o mal comportamento do mundo monorracial, hegemônico e monocultural.

Aqueles que usam os termos de forma reducionista, dando conotação com sentido de punir, invisibilizar e negar histórias plurais que desmentem uma visão de poder e subalternizações. Desta forma, propomos o holísmo como ferramenta na visão de mundo. Pois, as ideias ancoradas no holísmo corroboram com os temas trazidos pelos mitos já que sua abordagem revela assuntos do passado que irão coadunarem com as interdisciplinaridades do mundo contemporâneo. Atualizando as atividades desenvolvidas em sala de aula, mostrando a necessidade da proposta quando são posta à luz de uma pedagogia que Walsh (2007) revela com a interculturalidade.

Para Eliade (1963) a definição do mito pode ser complexa, pois envolve a cultura de um povo e todo o cenário mítico. Ao estudar um mito devemos saber que ensinamento iremos extrair deste acontecimento para podermos incluir numa nova perspectiva e, assim aprendermos com ele. Muitas vezes falamos sobre o mito como histórias simplistas e esquecemos de abordar e enraizar as questões imbrincadas entre o passado e presente, tornando estes diálogos sempre atuais para a educação.

Saber diferenciar as histórias mitológicas verdadeiras das que chamam de falsas, 'contos e/ou fábulas' é fundamental. Neste contexto, é importante aprofundar leituras dos diversos mitos e extrair deles suas essências necessárias para a vida humana, animal, vegetal, espiritual que são relatadas em diversas fases em que ocorrem os fatos sociais. Para Eliade (1972, p.v17), “[...] conhecer os mitos é aprender o sentido da origem das coisas $[\ldots] "$.

Neste interim, propomos a educação como viés propulsor para debatermos o mito 'da Caixa de Pandora e a Tentação de Eva' para desconstruir a figura do poder masculino sobre o corpo feminino que a tempos configura como hegemônico e dilacera todas as 
oportunidades que surgem com a mulher sendo protagonista. Está enraizada na cultura da sociedade machista que o lugar da mulher será a sombra do homem, isto é, sempre por trás dele.

Freire (1992) protagonizou o termo 'sulear' como expressão para dar outro sentido ao deslocamento que devemos traçar para encontrar os conhecimentos presente que ainda lutam para sair da invisibilidade. Para isso, devemos implantar e implementar projetos para podermos descaracterizá-los, já que o grupo hegemônico normatiza os trabalhos acadêmicos aos olhos eurocêntricos. Sem dar conta da grande gama de pedagogias e temas que existem espalhados pelo globo terrestre. O 'sulear' é fazer o caminho avesso aos que permeiam hoje a forma de pensar a educação.

Parafraseando Freire (1992), neste princípio, a tese sulear, nos ensina que devemos procurar outro rumo, não mais o nortear e sim o sul. Que são formas de debater e criar possíveis e imagináveis soluções para que possamos descolonizar olhos, vozes, mentes toda forma de replicar conhecimento hegemônicos usado pelo patriarcado.

Pensar o mito como viés para educação é fazer afirmar o extenso pensamento sulear freiriano, que tem na sua biografia as escritas de um mundo de oprimidos(as), opressores(as), questionamentos e de saídas que devem ser levadas à luz da sociedade de forma transparente e educativa. Sendo a 'práxis' sua real forma de aprender a aprender. No tocante a Pedagogia do Oprimido (1987), sempre que houver um subalternizador(a) sempre terá na outra extremidade o subalterno(a), sem um não haverá o outro.

No que toca o subalterno a autora indiana Gayatri Chakravorty Spivak (2010) na sua obra 'Pode o subalterno falar?' faremos um breve recorte do assunto tratado pela autora para enfatizar as questões que envolve o nosso artigo cientifico. Pois trataremos do assunto com base na subalternização do gênero feminino que também é tocado em seu ensaio com as questões pós-coloniais.

Assevera a autora, que o termo subalterno não pode desvincular-se da ideia gramsciniana de 'proletariado' o ser invisibilizado, sem vez e voz. Como também ao se referir a este personagem seja um ato imbricado a hegemonia. Negando seu uso para outros seres sociais de classes reprimidas. Para Spivak (2010, p. 16-17). 


\begin{abstract}
A fala do subalterno e do colonizado ser sempre intermediada pela voz de outrem, que se coloca em posição de reivindicar algo em nome de um (a) outro (a). Esse argumento destaca, acima de tudo, a ilusão e a cumplicidade do intelectual que crê poder falar por esse outro (a). A tarefa do intelectual póscolonial deve ser a de criar espaços por meio dos quais o sujeito subalterno possa falar para que, quando ele ou ela o faça, possa ser ouvido (a). Não se pode falar pelo subalterno, mas pode-se trabalhar 'contra' a subalternidade, criando espaços nos quais o subalterno possa se articular e, como consequência, possa também ser ouvido.
\end{abstract}

Concordando com os questionamentos trazidos por Spivak (2014) assegurando que o lugar de onde fala o sujeito subalterno poderá ser construído como uma plataforma para que possa a vir ter vez, voz e visibilidade como oportunidade de ser presente na sociedade paternalista que castram as mulheres protagonista deste enredo. Entretanto, Freire (1992) sugeri o 'sulear' que traça uma nova rota descolando-se para encontrar soluções outras para um novo aprender com o mito.

Destarte, o livro 'rumo a uma nova didática' de Candau (2013) que traz seus contributos com base nas informações dita por Spivak (2010) ao colaborar com a ideia de (re)fazer uma didática que servisse de base para uma nova forma de mediar conhecimentos que contemple as camadas dos atores sociais concretos que lutam contra a subalternidade, patriarcal e clã hegemônico.

Esse núcleo didático com três fases/estruturas: humana, política e a técnica chamada pela autora de multidimensionalidade, multidimensão e/ou multidimensional. São dimensões estabelecidas e calcadas numa trajetória com pesquisas que foi criada para o professor como mediador do ser humano. Possa vir aproxima-se cada vez mais da realidade complexa do seu educando, adquirindo experiências sociais, pois somos seres políticos. Em analogia ao pensar de Basarab Nicolescu (1997) no ensaio 'A evolução transdisciplinar à universidade condição para o desenvolvimento sustentável' essas três fases multidimensionais de Candau (2013) humana, política e técnica podem serem vistas como uma só flecha apontado para um único alvo: o conhecimento. 
Sem torna-la um formalismo hegemônico ${ }^{4}$, são possibilidades que podemos alcançar positivamente para chegarmos aos questionamentos com o mito de 'Pandora e Eva”. Sem proposta dicotômica, excludente e preconceituosa e sim nas junções de ideias que formam entendimentos clarificados com significados positivos para o campo feminino.

A multidimensionalidade técnica não é tecnicismo e, sim a unicidade das metodologias com as teorias das aprendizagens, que amplificam os pensamentos e (re)descobrindo novos rumos para uma nova prática com significados. Política, engaja-se com o cunho social, adicionando aos atores sociais concretos suas classes, culturais, históricos e econômicos num quadro importante na hora de dialogar com os questionamentos que o mito abordará.

A dimensão humana é o complemento indissociável deste processo, sendo um importante núcleo que cuida da parte do outro com o uso do exercício da alteridade que alcança a equidade. Esse tripé é fundamental para se construir uma nova perspectiva para estudar o mito, mas, também como meios para formar o professor e a reformulação do currículo engessado.

As IES podem usar da pesquisa de Candau (2013) em seus cursos universitários que formam novos professores, pois estes saíram aptos para usarem a nova didática como base para seus discursos em sala de aulas e projetarem olhares com alteridades para seus educandos. Que nas vivências de mundos com as mulheres irão aprender a respeitar e terem tratamento humanos e cordiais.

Para tanto, a pedagogia da pluriversalidade desenvolvida no artigo tratado pelo filósofo Nogueira (2012) aponta para a desconstrução de um 'currículo universal', a priori, atesta que a humanidade é um grupo igual, negando que somos diferentes e, que

\footnotetext{
${ }^{4}$ O termo 'hegemonia' é usado por Grasmci como ação do grupo dominante pesquisado no Caderno do cárceres. Os Intelectuais. O princípio educativo. Jornalismo, v. 2, 2. ed. Rio de Janeiro: Civilização Brasileira. 2004. p. 21.

${ }^{5}$ Reivindicar que só há uma filosofia “universal” sem cultura, sexo, religião, história ou cor, é afirmar que a particularidade é um ponto de partida válido para a filosofia. Esta reivindicação não é explicitamente reconhecida com frequência pelos protagonistas da "universalidade" da filosofia. Esta é a razão pela qual eles estão dispostos a reconhecer nomes como Filosofia Ocidental, Chinesa, Indiana, Japonesa ou Russa, mas se recusam a reconhecer Filosofia Africana, Australasiana, Latino-americana, Maia e (até) mesmo filosofias feministas. Mongobe B. Ramose. Ensaios Filosóficos, Volume IV - outubro/2011 p. 11.
} 
tem como base constituída na forma ocidental de ver o mundo. Pois, são referências de um currículo centrado numa diretriz que dialoga apenas com seu construtor. Descaracterizando as produções acadêmicas com seus teóricos, atestando sua inferioridade fazendo refém dos saberes.

Para Nogueira (2012) a pluriversalidade estará sempre presente como composição de saberes outros e que faz as práticas pedagógicas serem mais interessantes aos serem transversalizadas. A pedagogia da pluriversalidade, coaduna com os demais saberes e torna esse em fundamental na composição geral, diz que todas as outras perspectivas são reais e possíveis pois não existem monuculturas e sim saberes criados diariamente por culturas diversas.

Podemos afirmar com o pensamento de Nogueira (2012) que ao inserir no mitos de 'Pandora e Eva' o feminino como tema, positivamente se faz presente a pedagogia pluriversal que abrirá portas para cristalizar a visão de subalternização imbricada no discurso. Ressalta Spivak (2010, p. 17) "Se, no contexto da produção colonial, o sujeito subalterno não tem história e não pode falar, o sujeito subalterno feminino está ainda mais profundamente na obscuridade."

O pensamento filosófico abordado pelo professor Nogueira nos ensina que os estudos com a pluriversalidade reconhece que a uma grande necessidade de se levar para a sala de aula os vários questionamentos inclusive os de gêneros. Para que sejam postos abertamente sua evolução e/as modificações dos seres humanos durante as suas existências nas sociedades.

Para a ciência o que nos define como seres humanos é nosso raciocínio, inteligência, subjetividade que em contextos diferentes deverá ser analisado, pois somos culturalmente distintos. Parafraseando Nogueira (2012) para os seres humanos monorracionais uma única visão distinta, para os polirracionais múltiplas perspectivas assimiladas.

Walsh (2007) nos revela que a interculturalidade deve ser conceituada como um outro pensamento, modos de vivências que foge do real que foi amarrado e deixado pelo colonizador. Pois, contribuímos para uma sociedade excludente, devido a forma como somos educados cognitivamente. Pensando e agindo com a mente dos colonizadores que desqualificar o outro, separamos por classes sociais, religiões, pela cor da pele, pelo saber, 
ter. Devemos usar as interculturalidades como viés engrandecedor e que nos mostra uma saída para este caos epistemológico.

Para isso, devemos usar da pedagogia decolonial, intercultural, críticas e etc, com seus teóricos pós-coloniais que nos ensinam que os estudos e seus desdobramentos como graduações, mestrados, doutorados, pesquisas, livros, artigos entre outros construtos contra hegemônicos são necessários para lutarmos contra um pensamento global neoliberal que nos torna refém e quer a todo modo que nos tornemos subalternos (as).

Portanto, a autora com sua visão intercultural nos presentei com uma grande teia afirmando que a função histórica, social, política, cultural e econômica das sociedades são peças fundamentais quando levado para as escolas e IES os temas com a interculturalidade. Criando possibilidades de reconstrói o currículo que potencializa suas estruturas e afirmando a existências de saberes e fazeres até então não levado para discursão nas instituições de ensino. Desta forma, criar espaços para informações acerca do tema usando o mito feminino como ancoradouro para desmistificar certos assuntos e tabus. Será importantíssimo sendo mais uma nova forma de transpor barreiras do patriarcado criando novas perspectivas que faça do grupo feminino ter seu espaço respeitado para que se possa desenvolver uma sociedade com equidade.

\section{CONSIDERAÇÕES FINAIS}

Conclui-se que os mitos de Pandora e Eva, ambos em contextos criacionistas estão carregados de uma linguagem extremamente machista, dado ao contexto dos sociedades humanas em que surgiram: helenismo e semitismo. Percebemos que a mulher foi responsabilizada pelas más condições de vida da humanidade seja na dimensão social caso de Pandora - doenças, inveja, desgraças, etc.; seja mais no espiritual, caso de Eva pecado.

Constata-se que o conteúdo pedagógico implícito em cada um destes mitos é transmitir de geração em geração que a humanidade era boa e não conhecia o mal, até que a mulher desobedeceu a uma ordem de uma divindade masculina e como consequência o mal se faz presente e se naturaliza no mundo dos homens. 
Por outro lado, propomos uma utilização pedagógica positivada dos mitos em sala de aula, para levar os estudantes a repensarem a realidade atual, a partir dos mitos, a fim de desmistificar os preconceitos contemporâneos para que os estudantes tornem-se pessoas mais compreensíveis e tolerantes como o diferente, aceitando que o outro também é uma pessoa e que ela não é responsável por certas circunstâncias malévolas que por ventura eu tenha que enfrentar em minha vida.

Portanto, os mitos podem corroborar para que a sociedade possa reler e rever certos comportamentos que menosprezam as outras pessoas tornando-as inferiorizadas e responsabilizadas pelos males existentes no mundo. Uma adequada reflexão com os alunos em sala de aula pode modificar sua concepção de mundo, levando-os à uma nova cosmovisão, mais holística e mais humanizada.

\section{REFERÊNCIAS}

CAMPBELL, J. O Poder do Mito. São Paulo: Palas Athena.1990.

CANDAU, Vera Maria (Org.). Rumo uma Nova Didática. 23. ed. Petrópolis: Vozes, 2013.

CONFERENCIA NACIONAL DOS BISPOS DO BRASIL. Bíblia Sagrada. Tradução da CNBB. Brasília: CNBB, 2012.

ELIADE, M. Aspectos do Mito, Edições 70, Lisboa. 1989

Mito e Real idade Debate e Filosofia. São Paulo: Perspectiva. 1972.

FREIRE. P. Paulo Freire adere ao SULear: Extratos de Paulo Freire e Ana Maria "Nita" Freire sobre SULear. Disponível em: <www.sulear.com.br> Acessado em: 13 Jan.2019

Pedagogia do Oprimido 17. ed. Rio de Janeiro: Paz e Terra, 1987.

GRAMSCI. A. Caderno do cárcere. Os Intelectuais. O princípio educativo. Jornalismo, v. 2, 2. ed. Rio de Janeiro: Civilização Brasileira. 2004. p. 21.

GIL, Antonio Carlos. Como Elaborar Projeto de Pesquisa. 5. ed. São Paulo: Atlas, 2010.

HEFESTO (VULCANO). In: CHEVALIER, Jean; GHEERBRANT, Alain, [et al]. Dicionário de Símbolos: mitos, sonhos, costumes, gestos, formas, figuras, cores, números. Tradução de Vera da Costa Silva [et. al.]. 23. ed. Rio de Janeiro: José Olympio, 2009. p. 485. 
MATTALLO JUNIOR, Heitor. MITO, METAFÍSICA, CIÊNCIA E VERDADE. In: CARVALHO, Maria Cecília M. de (Org). Construindo o Saber: metodologia científica, fundamentos e técnicas. 15. ed. Campinas: Papirus, 2003. p. 29-37.

NICOLESCU, B. A Evolução transdisciplinar a universidade condição para o desenvolvimento sustentável. Disponível em: <http://cirettransdisciplinarity.org/bulletin/b12c8por.php\#>. Acessado em. <12 Mar. 2019>.

NOGUERA, Renato. Denegrindo a educação: Um ensaio filosófico para uma pedagogia da pluriversalidade. Revista Sul-Americana de Filosofia e Educação. Número 18: maio- out/2012, p. 62-73.

PANDORA. In: CHEVALIER, Jean; GHEERBRANT, Alain, [et al]. Dicionário de Símbolos: mitos, sonhos, costumes, gestos, formas, figuras, cores, números. Tradução de Vera da Costa Silva [et. al.]. 23. ed. Rio de Janeiro: José Olympio, 2009. p. 680-681.

RAMOSE, B M. Sobre a Legitimidade e o Estudo da Filosofia Africana. Ensaios Filosóficos, Volume IV - outubro/2011 p. 11. Disponível em: <http://www.ensaiosfilosoficos.com.br/Artigos/Artigo4/RAMOSE_MB.pdf >. Acessado em: <12 Mar. 2019>

SPIVAK, G.C. Pode o subalterno falar? Belo Horizonte: UFMG 2010, p. 16-17.

WALSH, Catherine. Interculturalidad critica/ pedagogia decolonial. (2007). In: Anais do Seminário Internacional Diversidad, Interculturalidad y Construcción de Ciudad. Bogotá: Universidad Pedagógica Nacional. 